
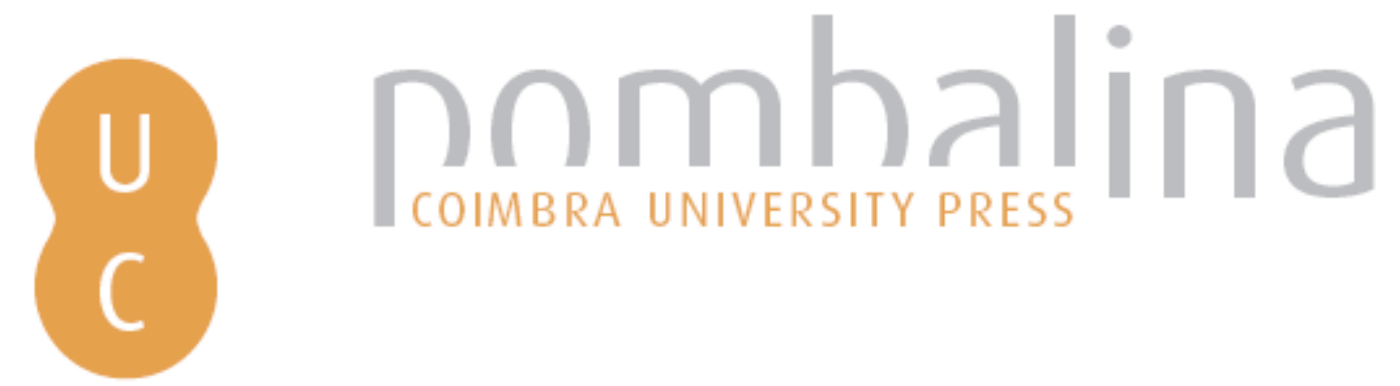

\title{
Traduções alemãs do marcador 'aliás': uma análise do corpus Europarl
}

Autor(es): $\quad$ Plag, Cornelia; Loureiro, Ana Paula; Carapinha, Conceição

Publicado por: Imprensa da Universidade de Coimbra

URL

persistente: URI:http://hdl.handle.net/10316.2/43266

DOI: $\quad$ DOl:https://doi.org/10.14195/978-989-26-1446-5_5

Accessed : $\quad$ 26-Apr-2023 13:07:23

A navegação consulta e descarregamento dos títulos inseridos nas Bibliotecas Digitais UC Digitalis, UC Pombalina e UC Impactum, pressupõem a aceitação plena e sem reservas dos Termos e Condições de Uso destas Bibliotecas Digitais, disponíveis em https://digitalis.uc.pt/pt-pt/termos.

Conforme exposto nos referidos Termos e Condições de Uso, o descarregamento de títulos de acesso restrito requer uma licença válida de autorização devendo o utilizador aceder ao(s) documento(s) a partir de um endereço de IP da instituição detentora da supramencionada licença.

Ao utilizador é apenas permitido o descarregamento para uso pessoal, pelo que o emprego do(s) título(s) descarregado(s) para outro fim, designadamente comercial, carece de autorização do respetivo autor ou editor da obra.

Na medida em que todas as obras da UC Digitalis se encontram protegidas pelo Código do Direito de Autor e Direitos Conexos e demais legislação aplicável, toda a cópia, parcial ou total, deste documento, nos casos em que é legalmente admitida, deverá conter ou fazer-se acompanhar por este aviso. 
(1) ANA PAULA LOUREIRO GONCEIÇÃO CARAPINHA CORNELIA PLAG

1 (ICOORDS.)

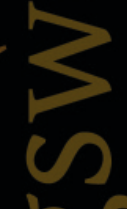

bo

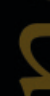

구구요

?ubrigens

(1)

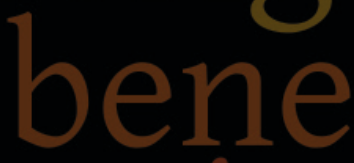

$\bullet$

N

assing

(1)

(2)

MARCADORES

DISCURSIVOS

E(M)

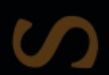

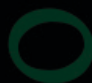

10

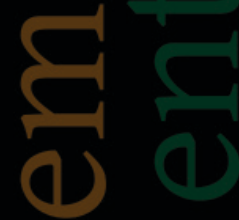

तु

\section{(}

(1)
IMPRENSA DA

UNIVERSIDADE

DE COIMBRA

COIMBRA

UNIVERSITY

PRESS

affettiv 


\title{
TRADUÇÕ ESALEMÃS DOMARCADOR 'ALIÁS' UMA A NÁLISE DO CORPUS EUROPARL
}

\author{
Cornelia Plag \\ (Universidade de Coimbra - CELGA-ILTEC) \\ cornelia.plag@fl.uc.pt \\ Ana Paula Loureiro \\ (Universidade de Coimbra - CELGA-ILTEC) \\ olivelou@ci.uc.pt \\ Conceição Carapinha \\ (Universidade de Coimbra - CELGA-ILTEC) \\ mccarapinha@fl.uc.pt
}

\begin{abstract}
Resumo: Este trabalho visa analisar a tradução do marcador discursivo 'aliás' para a língua alemã, bem como explorar as diferentes propostas apresentadas por tradutores profissionais a respeito deste item. Com base em pesquisas anteriores já efetuadas sobre as funções deste marcador em língua portuguesa, o estudo descreve as convergências e as divergências encontradas entre 'aliás' e os seus equivalentes alemães numa amostra extraída do corpus Europarl. A pesquisa revela que 'aliás' ativa diferentes clusters semânticos em português e demonstra a preferência dos tradutores por um pequeno conjunto de marcadores de discurso alemães. A análise contrastiva também comprova que 'aliás' tem um leque mais alargado de funções semânticas do que os seus equivalentes em língua alemã e confirma a existência de uma função que nunca é traduzida.
\end{abstract}

Palavras-chave: Marcador discursivo; tradução; aliás; clusters semânticos; corpus Europarl 


\begin{abstract}
The aim of this paper is to analyze the translation of the discourse marker 'aliás' from Portuguese into German and to explore the different proposals put forward by professional translators about this particular item. Drawing on previous research about the functions of this specific marker in Portuguese language this study analyses the convergences and the divergences of Portuguese 'aliás' and its German equivalents in an excerpt of Europarl corpus. The study reveals that 'aliás' activates different semantic clusters in Portuguese and demonstrates the preference for a small set of German discourse markers in a significant part of the translations. The contrastive analysis also shows that 'aliás' has a larger semantic range than its equivalents and confirms the existence of a function which is not translated.
\end{abstract}

Key words: Discourse marker, translation, aliás, semantic clusters, Europarl corpus

\title{
0. Introdução
}

A designação 'marcadores discursivos' (doravante MD) abrange um vasto conjunto de expressões usadas para conectar enunciados e outros segmentos textuais de maior ou menor extensão. A diversidade categorial de itens subsumíveis sob esta designação e a multiplicidade de funções que cada um é capaz de desempenhar em contexto determinam as reconhecidas dificuldades em os identificar e definir de modo adequado. A este respeito, Andersen (2001: 39) lembra que "there seems to be little consensus as to how this category ought to be defined and delimited and as to which items constitute the inventory of pragmatic markers (...)."1

Constituindo um grupo categorialmente heterogéneo, de distribuição desigual e com funcionalidades distintas, é possível, ainda assim, atribuir aos MD um conjunto de caraterísticas que de

\footnotetext{
${ }^{1}$ Esta continua a ser - algumas décadas passadas sobre os primeiros estudos sobre MD - uma das questões centrais na área.
} 
alguma forma os definem e que sobressaem na já vasta bibliografia relativa ao tópico.

A primeira, a que mais se salienta, e que constitui a base para muitas das definições propostas para a categoria, é precisamente a conectividade (Schiffrin, 1987; Schourup, 1999; Degand, 2009), isto é, a sua capacidade de articular fragmentos discursivos, assinalando uma relação "between the interpretation of the segment they introduce, S2, and the prior segment, S1" (Fraser, 1999: 931). Neste sentido, os MD funcionam como pistas que permitem otimizar o processo interpretativo, e, no fundo, criar coerência. Em clara relação com a conectividade, uma outra característica, já assinalada por Hölker (1991), diz respeito à não contribuição dos MD para o conteúdo proposicional dos enunciados em que ocorrem, uma vez que o seu significado é meramente procedimental, equivalendo a um conjunto de instruções acerca de como interpretar o enunciado. $\mathrm{O}$ mesmo autor refere a função essencialmente emotiva e expressiva dos MD, mais do que denotativa ou referencial, e Bazzanella et al. (2007) salientam, por outro lado, a extrema sensibilidade às variações co- e contextuais como outra das caraterísticas típicas do comportamento destes itens no discurso.

Todas as línguas recorrem a estas partículas, quer no discurso oral quer no escrito, para sustentar a coesão, para guiar a interpretação dos ouvintes/leitores, para expressar uma atitude; fazem-no, no entanto, de modos diversos, pois "across languages there is divergence in their usage, placement, and frequency" (Steele, 2015: 110).

Os múltiplos estudos que, sob diversas perspetivas, têm vindo a ser publicados sobre o tema dos MD abarcam agora, também, a perspetiva tradutológica. É, aliás, recorrentemente referida a importância dos contributos trazidos pelos estudos em tradução para um conhecimento mais fino destas partículas. Como afirmam Aijmer et al. (2006: 113) "comparing translations of a text in different langua- 
ges can help to reveal the meaning of markers which might be less accessible in a monolingual approach." 2

A tradução procura produzir, na língua de chegada (LC), um texto funcionalmente adequado, o que pode passar - entre outras estratégias possíveis - pela escolha de uma expressão que mantenha o mesmo valor da língua original. Mas será tal procedimento sempre exequível quando é necessário traduzir um MD? A sua extrema dependência do contexto, a sua inerente indeterminação semântica e a sua polifuncionalidade complexificam a tarefa de os traduzir.

Chaume (2004: 844) alerta precisamente para o facto de eles constituírem "a usual pitfall in (...) translating" e Bazzanella et al. (2007: 11) corroboram esta opinião ao afirmar que "translating DMs appears to be particularly difficult, much more so than in the case of other parts of speech, since words used in a DM function are 'indeterminate' per se, and one can determine DMs only with regard to the specific usage in context."

De facto, e uma vez que assumem uma função essencialmente pragmática, sem intervenção direta na construção dos conteúdos proposicionais, os MD que surgem num determinado ponto da sequência discursiva recebem muitas vezes, da parte do tradutor, um tratamento desigual que os coloca num plano inferior face a outras prioridades tradutivas. $\mathrm{E}$ as diferentes soluções encontradas para a tradução de um MD podem abranger o recurso a estratégias lexicais, sintáticas, mas podem também chegar à omissão.

\footnotetext{
2 Esse interesse dos estudos de tradução materializa-se em dois grandes tipos de análise. De uma perspetiva semasiológica, parte-se de um determinado termo para chegar à análise do sentido, permitindo testar, de um enfoque tradutório, se equivalentes lexicográficos (em duas línguas distintas) recobrem ou não o mesmo leque de valores. De um ponto de vista onomasiológico, parte-se de um conceito para chegar às formas que o consubstanciam, o que, no âmbito tradutório, permite chegar às certamente diferentes representações lexicais do conceito, em cada uma das línguas.
} 
$\mathrm{Na}$ interface destas duas áreas de investigação, este trabalho apresenta um estudo contrastivo sobre o MD 'áliás' em contexto de tradução, no par de línguas português-alemão. Ancorado num quadro teórico cognitivo-funcional, o estudo parte de uma abordagem polissémica dos MD, advogando que os diferentes sentidos de uma partícula não devem ser entendidos como discretos, mas antes relacionados, "in a chain-like fashion", (Hansen, 1998: 87), através de semelhanças de família, configurando um continuum em que as fronteiras entre os seus diferentes valores são vagas e imprecisas e em que há claras zonas de sobreposição.

Trabalhando numa perspetiva semasiológica, e tendo por referência os valores elencados para 'aliás' em português, (Lopes, 2010; Ponce de León \& Duarte, 2013; e Almeida, 2013), serão confrontadas as ocorrências deste MD com os equivalentes encontrados no texto alemão. Os objetivos deste estudo são os seguintes: (i) encontrar os equivalentes funcionais de 'aliás' na LC; (ii) sistematizar as possíveis convergências e divergências de sentido (iii) confrontar os dados recolhidos com as informações disponíveis nos dicionários. Os dados empíricos que sustentam a análise são provenientes do corpus Europarl (Koehn, 2005), um acervo multilingue de dados resultantes de debates ocorridos no Parlamento Europeu.

A estrutura deste trabalho é a seguinte: num primeiro momento, apresentaremos, de forma sucinta, os diferentes valores de 'aliás' na atual sincronia do Português; a secção seguinte dará conta das opções metodológicas por nós tomadas e do grande interesse de um corpus traduzido como ferramenta heurística para obter informações sobre a semântica dos MD; de seguida, apresentar-se-ão os resultados obtidos e a respetiva análise; finalizaremos com uma pequena secção de conclusões. 


\section{Os diferentes valores de 'aliás' na atual sincronia do Português}

O item 'aliás' é apresentado como advérbio pelos dicionários de referência da língua portuguesa. O Dicionário da Língua Portuguesa Contemporânea, da Academia das Ciências de Lisboa (2001) avança, na definição da partícula, as seguintes aceções:

(i) arc. Hipótese de polaridade contrária;

(ii) marcador de correção;

(iii) marcador de digressão;

(iv) bordão linguístico;

(v) utensílio metalexical (uso de Macau).

No Dicionário Houaiss da Língua Portuguesa (2002), 'aliás' assume os seguintes valores:

(i) sinalizador de situação hipotética alternativa à situação avançada anteriormente;

(ii) marcador de reforço;

(iii) marcador de correção/retificação;

(iv) marcador de digressão;

(v) marcador contrastivo.

Nas gramáticas, o item 'aliás' é identificado como partícula de retificação e surge incluído no grupo, heterogéneo, das 'palavras denotativas', (Cunha e Cintra, 1984: 549) ou 'denotadoras' (Bechara, 2005: 291), grupo que, segundo o autor brasileiro, diz respeito a um grande conjunto de palavras "muitas das quais têm papel transfrástico e melhor atendem a fatores de função textual (...)." Sob este ponto de vista, a apreciação do gramático brasileiro converge com as funções dos marcadores anteriormente apresentadas.

Já no domínio da investigação, e especificamente sobre esta partícula, salientam-se os trabalhos de Lopes (2010), Ponce de León 
e Duarte (2013) e Almeida (2013). A indicação de duas funções é comum aos quatro autores: 'aliás' é um marcador que sinaliza uma digressão, indicando a adição de um mero comentário lateral (Lopes, 2010) ou, em alternativa, a adição de um argumento mais forte para reforçar uma linha argumentativa, (Ponce de León e Duarte, 2013) e também pode ser um marcador de reformulação e/ou retificação. Ponce de León e Duarte acrescentam ainda uma outra possível função do marcador: 'aliás' pode igualmente ser usado para assinalar a mudança de tópico discursivo, à semelhança de um organizador textual.

No cômputo de todas estas informações, sobressaem três funções do MD na atual sincronia do português:

(i) sinalizar a iminência de uma reformulação (que pode até ser uma retificação);

(ii) sinalizar a presença de um segmento discursivo de natureza digressiva, dotado de um estatuto parentético;

(iii) sinalizar a adição de mais um argumento, neste caso, decisivo (Koch, 1984: 196) e, neste sentido, funcionar já como um marcador de reforço argumentativo [sentido que também é assinalado pelo Dicionário Houaiss da Língua Portuguesaaceção(ii)].

Vejamos exemplos que atestam todos estes valores ${ }^{3}:$

(1) reformulação

par $=$ ext658657-nd-95b-1: Mas escrevi esta carta por causa dos belos poemas de Gedeão, aliás Rómulo de Carvalho, que conheci como professor no Liceu D. João III, em Coimbra.

3 Os exemplos aqui inseridos foram recolhidos no CETEMPúblico, um corpus de imprensa contemporânea escrita, disponível online em $<$ http://acdc.linguateca.pt $>$. 
(2) digressão com introdução de tópico lateral par=ext196238-clt-92b-2: Para terminar, pode dizer-se que esta tendência para o silêncio (aliás salientada por João Barrento no seu belo prefácio) talvez se perceba levando em conta dois aspectos: por um lado, uma irresistível atracção pela morte como a serenidade maior e mais profunda, como um "grande silêncio" (...).

(3) digressão com introdução de argumento decisivo par=ext403209-soc-98a-2: Mas a área que aparentemente é mais frágil na introdução dos conteúdos no Oceanário é a da captura e fornecimento das espécies, como aliás o demonstra o facto de não ser conhecida com rigor a área de proveniência do lote de tubarões que adoeceram.

Os diferentes matizes de sentido deste item parecem convergir, tal como afirmam Ponce de León e Duarte (2013: 146) para o valor etimológico de 'aliás' que, de acordo com o Dicionário Houaiss era, em latim: "outra vez, outras vezes, noutro momento, noutra época, de outro modo, etc." Com efeito, este parece ser o semantismo básico do MD: sinalizar a introdução de outro enunciado, que pode constituir uma operação metadiscursiva de reformulação do dito, atuando no plano do autocontrolo discursivo (Fernandes, 2005); ou assinalar a operação argumentativa de aditamento de uma outra informação, atuando no plano temático-informacional.

Uma abordagem dos dicionários bilingues, na direção português-alemão, tanto impressos (Langenscheidt) como online (Pons e Leo), revela alguma dispersão quanto aos equivalentes sugeridos para o item 'aliás'.

O dicionário Langenscheidt apresenta os seguintes equivalentes: übrigens (a propósito; diga-se de passagem); jedoch (contudo); beziehungsweise (ou seja / ou antes / mais concretamente). 
Os dicionários online de português-alemão ampliam ainda mais as possibilidades tradutivas da partícula. O dicionário Pons propõe as seguintes traduções: übrigens (a propósito; diga-se de passagem); beziehungsweise (ou seja / ou antes / mais concretamente); sonst (caso contrário); obnebin (mesmo assim; de qualquer maneira). O dicionário Leo recomenda as expressões seguintes: übrigens (a propósito; diga-se de passagem); mit anderen Worten (ou melhor); außerdem (além disso); besser gesagt (ou melhor); das heißt (ou melhor); beziehungsweise (ou seja / ou antes / mais concretamente).

O dicionário online da Porto Editora propõe as seguintes traduções: beziehungsweise (ou seja / ou antes / mais concretamente); im Übrigen (de resto); obnehin (mesmo assim; de qualquer maneira); sonst (caso contrário); übrigens (a propósito; diga-se de passagem). No dicionário bab.la, a partícula é traduzida por zudem (além disso) e übrigens (a propósito; diga-se de passagem).

Observemos esquematicamente estes dados:

Quadro 1

\begin{tabular}{|l|l|l|l|l|l|}
\hline & Langenscheidt & Pons & Leo & Porto Editora & bab.la \\
\hline übrigens & $\sqrt{ }$ & $\sqrt{ }$ & $\sqrt{ }$ & $\sqrt{ }$ & $\sqrt{ }$ \\
\hline beziehungsweise & $\sqrt{ }$ & $\sqrt{ }$ & $\sqrt{ }$ & $\sqrt{ }$ & \\
\hline sonst & & $\sqrt{ }$ & & $\sqrt{ }$ & \\
\hline ohnehin & & & $\sqrt{ }$ & $\sqrt{ }$ & \\
\hline jedoch & $\sqrt{ }$ & & $\sqrt{ }$ & & \\
\hline $\begin{array}{l}\text { mit anderen Wor- } \\
\text { ten }\end{array}$ & & & $\sqrt{ }$ & & \\
\hline außerdem & & & $\sqrt{ }$ & & \\
\hline besser gesagt & & & $\sqrt{ }$ & & \\
\hline das heißt & & & & $\sqrt{ }$ & \\
\hline im Übrigen & & & & & $\sqrt{ }$ \\
\hline zudem & & & &
\end{tabular}

A análise deste quadro torna evidente a grande variedade de putativos equivalentes lexicográficos propostos pela língua alemã. As informações obtidas nestes cinco dicionários permitem concluir 
que apenas übrigens (a propósito; diga-se de passagem) é comum a todos eles e que apenas a expressão beziehungsweise (ou seja / ou antes / mais concretamente) é partilhada por quatro dicionários; todas as outras (nove) aparecem apenas num ou dois dicionários.

Podemos também concluir, por outro lado, que nenhum destes equivalentes partilha o mesmo leque de valores de 'aliás'. Com efeito, mesmo os dois marcadores alemães mais frequentes só parcialmente recobrem o valor de 'aliás': übrigens converge com o sentido digressivo e beziehungsweise, com o reformulativo-retificativo. E até as partículas sonst e ohnebin, comuns a dois dos dicionários, apresentam valores que 'aliás' não tem na atual sincronia do português: sonst tem um valor condicional-contrastivo, equivalente a 'caso contrário' ou 'senão', enquanto ohnehin pode ter dois valores: marcador de distanciamento, equivalendo a 'em todo o caso', e o valor de introdutor de fecho de tópico ou de fecho de digressão, equivalente à expressão portuguesa 'de qualquer maneira'4 .

\section{Algumas considerações de ordem teórico-metodológica}

O estudo contrastivo que efetuámos parte de dados empíricos recolhidos no corpus Europarl5 (Koehn, 2005), um corpus multilingue, envolvendo debates políticos ocorridos no Parlamento Europeu e as respetivas traduções paralelas nas vinte e uma línguas de trabalho. A opção por um corpus deste tipo possibilitou a escolha de discursos originalmente pronunciados por parlamentares portugueses, condição óbvia para a obtenção de dados autênticos produzidos por falantes nativos de português. Por outro lado,

\footnotetext{
${ }^{4}$ É ainda pertinente assinalar que jedoch também não se aproxima dos valores contemporâneos de 'aliás'.

5 Corpus acessível no sítio: <http://www.statmt.org/europarl/>.
} 
restringimos o intervalo temporal em análise aos períodos das presidências portuguesas (janeiro a junho de 2000 e julho a dezembro de 2007), períodos em que haveria maior probabilidade de encontrar oradores portugueses. Dada a facilidade em obter a correspondência entre o texto original e o traduzido, um corpus como este 6 consentiu uma pesquisa mais rápida e mais eficiente, pois a oportunidade de fazer alinhar o discurso original e o discurso traduzido permitiu ter uma perceção imediata da natureza da tradução efetuada. Com efeito, uma das vantagens deste tipo de corpora consiste na possibilidade de explorar concordâncias, isto é, apreender o cotexto, mais ou menos alargado, de todas as ocorrências de uma palavra.

Nesses intervalos temporais, detetámos 885 ocorrências de 'aliás', das quais 184 foram originalmente produzidas em português e não resultaram de opções tradutórias relativamente a outras línguas de partida. Foram essas 184 ocorrências, e as suas traduções em alemão, que constituíram o nosso corpus inicial.

Um corpus com esta extensão garantia, à partida, que todos os sentidos de 'aliás' previamente elencados estariam presentes, embora, sob outro ponto de vista, tal argumento pudesse ser rebatido tendo em conta tratar-se de um contexto institucional muito específico e de um género textual também ele particular, os quais poderiam promover o surgimento de alguns usos e não de outros. Para além deste último, outros argumentos podem ser aduzidos em sentido contrário ao uso deste tipo de corpora. Um deles diz respeito ao facto de o corpus traduzido apenas representar uma das possíveis traduções, proveniente de um tradutor, o que impede não só que os dados sobre os quais se trabalha sejam representativos, como também que outras traduções alternativas vejam a luz do dia; de

6 O corpus Europarl não corresponde exatamente ao protótipo de um corpus paralelo [língua de partida (LP) $\rightarrow$ língua de chegada (LC)], já que os enunciados são organizados por língua, independentemente da sua origem; daí cada subcorpus reunir quer enunciados originais quer traduzidos. 
facto, como afirma Snell-Hornby (1988: 20), "the opinions of the most competent translators can diverge considerably." Por outro lado, num contexto de interpretação simultânea, em que não é possível corrigir e voltar atrás, a opção de um tradutor não permite muita ponderação e pode não apenas vir a revelar-se inadequada tendo em conta a avaliação final do enunciado, como não ser aquela que o mesmo tradutor faria se tivesse, naquele contexto, mais tempo de reflexão. É ainda pertinente observar que, ao desconhecermos o número e a identidade dos tradutores envolvidos neste corpus, também corremos o risco de obter algum enviesamento da amostra.

Por último, uma análise unidirecional das traduções, como a que faremos neste estudo, apenas aclara parte do problema, tendo em conta que a retrotradução poderia desvendar outras correspondências.

Cientes destas fragilidades, cremos, ainda assim, que este método de análise, cross-linguistic, apresenta vantagens inequívocas. Em primeiro lugar, trata-se de dados autênticos que nos dão a garantia de estarmos a analisar a linguagem em uso; em segundo lugar, esses dados apresentam tendências tradutivas não negligenciáveis, na medida em que são o resultado do trabalho de profissionais; em terceiro lugar, aparecem já contextualizados e traduzidos na LC, sendo de fácil e rápido acesso. Por outro lado ainda, e parafraseando Aijmer, Foolen e Simon-Vandenbergen (2006) uma análise efetuada em corpora paralelos pode revelar sentidos (de um MD) que passam mais ignorados numa análise de natureza intralinguística.

De facto, "finding translation correspondences is in many ways a more reliable method of describing individual DMs than providing paraphrases and glosses, or establishing co-occurrence patterns, exemplified by the majority of monolingual research" (SimonVandenbergen e Aijmer, 2004: 1786). Ainda segundo as mesmas autoras, o uso de traduções para analisar MD pode também permitir equacionar questões mais amplas, relativas ao delineamento de campos semânticos nas diferentes línguas e à forma como esses campos 
podem ser diversamente instanciados em cada uma delas, facilitando a destrinça entre universais discursivos e traços que são específicos de determinadas línguas. A pesquisa dos equivalentes alemães de 'aliás' permitirá, pois, evidenciar as soluções adotadas relativamente aos casos, sempre problemáticos, de indeterminação ou de amálgama de sentidos contextualizados e demonstrar a forma como as línguas convergem ou divergem no que toca ao uso destas partículas.

\section{Análise e discussão dos resultados}

A complexa tarefa de delimitação de sentidos do MD 'aliás' [na língua de partida (LP)] tornou-se óbvia após uma primeira análise dos dados constantes do corpus. Com efeito, na grande maioria dos casos, os sentidos do MD encontram-se amalgamados e é difícil encontrar ocorrências de 'aliás' que instanciem apenas um dos sentidos previamente elencados. A existência de zonas de sobreposição implica que há sentidos próximos e até indestrinçáveis, configurando um cluster de sentidos. Tal facto vem corroborar a tese de que eles se apresentam num continuum, uma vez que os exemplos encontrados respondem bem a dois tipos de paráfrase distintos.

A análise a que sujeitámos o corpus fez sobressair esse continuum de valores do MD, que se apresentam da seguinte forma:

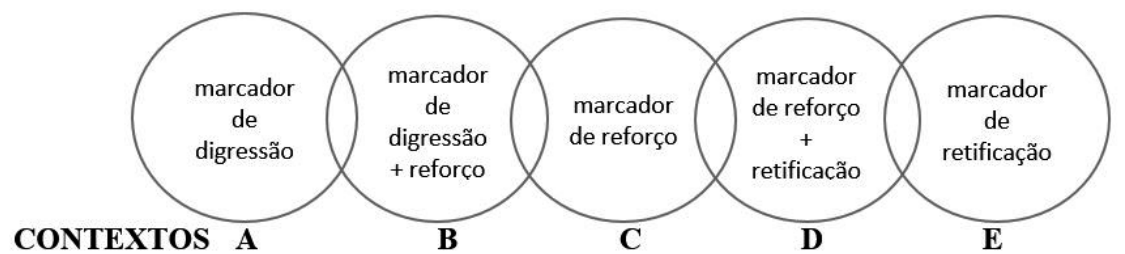

Vejamos alguns exemplos que ilustram todos os casos.

Contexto A - Marcador de digressão

Senhor Deputado, antes de mais, e comentando aquilo que disse o Senhor Presidente, quero dizer que tenho o maior prazer 
em estar sob o fogo dos deputados gregos - e tenho excelentes amigos na Grécia onde, aliás, passei férias. (00-04-12 <SPEAKER ID=188 NAME="Seixas da Costa">)

Neste excerto, 'aliás' introduz um comentário claramente parentético e sem aparente relevância em termos da argumentação expendida. $\mathrm{O}$ falante sinaliza que a expressão subsequente ao MD constitui um segmento lateral que constitui, apenas, um fait divers, uma informação da qual poderia prescindir sem fazer perigar o conteúdo proposicional principal. Neste tipo de contextos, 'aliás' pode ser substituído pelo marcador 'diga-se de passagem', o qual também introduz "un ajout non plannifié, évoqué de façon spontannée à la suite de l'énonciation du segment précédant" (Lopes, 2015: 346).

Contexto B - Marcador de digressão + Marcador de reforço A nossa leitura comum é que esse partido tem uma posição manifestamente contrária aos valores que temos por essenciais no quadro europeu e que, aliás, configuram o quadro de referência que a União tem vindo a promover nas suas relações externas, quer no tocante ao seu próximo alargamento, quer no quadro da sua política externa e de segurança comum. (00-02-02 <SPEAKER ID=13 NAME="Seixas da Costa">)

Num contexto como este, cremos que 'aliás' pode ter uma dupla leitura, por um lado como introdutor de uma informação suplementar, de natureza digressiva, apresentada como um dado já conhecido de todos, e também parafraseável por 'diga-se de passagem'; por outro, como sinalizador de um argumento decisivo e irrebatível de um ponto de vista argumentativo. Neste sentido, 'aliás' assinalaria o aditamento de uma informação que reforça uma estratégia argumentativa anterior e seria parafraseável por 'de facto' ou 'na realidade'. Teríamos, pois, aqui, um caso de cluster de sentidos em que aquilo que parece ser 
uma informação lateral pode também assumir o estatuto de argumento mais forte, sendo visível o continuum entre os dois sentidos.

Contexto C - Marcador de reforço

A verdade é esta: a Europa tem relações de parceria ao mais alto nível com a Ásia, onde há ditadores, e com a América Latina, onde também alguns países não são democracias, aliás alguns desses ditadores são recebidos com tapete vermelho em algumas capitais europeias. (07-07-11 <SPEAKER ID="051" NAME="José Manuel Barroso">)

Eis-nos perante um outro uso do marcador. 'Aliás' sinaliza explicitamente a introdução de um argumento decisivo na estratégia discursiva de crítica à atuação da Europa relativamente aos parceiros ditatoriais com os quais mantém relações. Numa escala argumentativa, e constituindo argumentos coorientados, o segundo argumento, introduzido por 'aliás', é mais forte e tem mais peso no que respeita à conclusão a que conduz. Como se torna evidente, neste contexto, 'aliás' não introduz um mero segmento parentético, mas sim o argumento mais importante, sendo, pois, parafraseável por 'de facto' ou 'na realidade'.

Contexto D - Marcador de reforço + marcador de retificação Pensamos que o papel da segurança alimentar, nomeadamente em tudo o que se liga à saúde pública, é um elemento fundamental a ser desenvolvido pela nossa Presidência; constitui, aliás, uma das prioridades do nosso programa. (00-01-19 <SPEAKER ID=163 NAME $=$ "Seixas da Costa">)

Neste exemplo, 'aliás' permite também uma dupla interpretação (tal como no anterior contexto B). Não só é parafraseável pelos marcadores 'de facto' e 'na realidade', o que o aproxima do sentido de reforço argumentativo, como também ilustra um contexto em 
que 'aliás' adquire um valor retificativo, isto é, parafraseável por 'ou melhor' ou 'ou antes'. Nestes contextos, o falante reformula e corrige o seu enunciado anterior, anulando a asserção prévia ou simplesmente, como na ocorrência em análise, escolhendo um argumento que, apesar de integrar a mesma escala argumentativa, é mais forte. Neste sentido, compreende-se a forma como a adição de um argumento de reforço da argumentação pode aproximar-se muito da reformulação (ou autorreformulação) retificativa. ${ }^{7}$

Relativamente ao contexto $\mathrm{E}$, a presença de 'aliás' com valor retificativo puro e inequívoco parece ser nula, no corpus em análise. Com efeito, os casos em que essa interpretação é admissível coincidem sempre com os contextos em que é também permitida uma leitura reforçativa, o que nos reconduz ao contexto $\mathrm{D}$.

No corpus em análise, os diferentes valores de 'aliás' distribuem-se da seguinte forma: o valor reforçativo, em que o MD prefacia os argumentos de maior influência na argumentação, é o mais frequente (contexto $\mathrm{C}$ ); o cluster que associa o valor digressivo ao valor reforçativo é o segundo mais frequente (contexto B); em terceiro lugar, surge a amálgama entre o valor reforçativo e o retificativo (contexto D). São pouco frequentes as ocorrências de 'aliás' como mero marcador digressivo (contexto A) e não foram detetadas ocorrências do valor retificativo puro (contexto $\mathrm{E}$ ).

Se observarmos agora o corpus traduzido, verificaremos que o total de equivalentes propostos na língua alemã para as 184 ocorrências de 'aliás' é de 24.

Os resultados obtidos aparecem expostos, por ordem alfabética, nas duas colunas do quadro seguinte, em que assinalámos a negrito as opções mais utilizadas:

\footnotetext{
7 Naturalmente, há constrições sintáticas associadas aos marcadores retificativos clássicos que não afetam aliás; 'ou melhor' e 'ou antes' prefaciam sempre um constituinte proposicional e só podem surgir antes desse constituinte, ao contrário do que acontece com 'aliás', que apresenta maior mobilidade na frase.
} 
Quadro 2

\begin{tabular}{|l|l|l|l|}
\hline abgesehen davon & 1 & eindeutig & 1 \\
\hline allein schon & 1 & ferner & 1 \\
\hline auch & $\mathbf{1 8}$ & im Übrigen & $\mathbf{6 3}$ \\
\hline auch noch & 1 & ja & 2 \\
\hline außerdem & $\mathbf{1 5}$ & ja auch & 1 \\
\hline außerdem da & 1 & ja im Übrigen & 1 \\
\hline außerdem ja & 1 & mehr noch & 2 \\
\hline bereits & 2 & nebenbei bemerkt & 2 \\
\hline dann & 1 & $\varnothing$ & $\mathbf{3 8}$ \\
\hline darüber hinaus & 2 & überdies & 1 \\
\hline darüber & 1 & übrigens & $\mathbf{1 6}$ \\
\hline ebenfalls & 1 & zudem & $\mathbf{1 1}$ \\
\hline
\end{tabular}

Uma simples observação do quadro anterior permite constatar que o corpus devolveu resultados que divergem bastante do leque de equivalentes esperados (se atendermos às propostas lexicográficas).

O quadro 3 exibe uma leitura estatística das opções mais frequentes:

Quadro 3

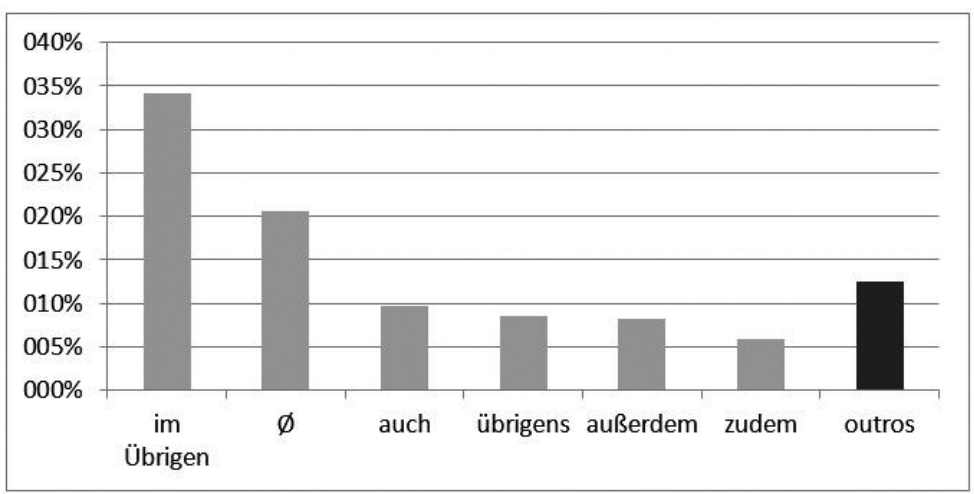

É visível a relação de um MD na LP para muitos na LC e essa dispersão não se dá apenas em termos numéricos, mas também no plano semântico. É de assinalar a opção dos tradutores (cerca de $35 \%$ dos casos) por uma expressão - im Übrigen (de resto) - que, 
curiosamente, não consta dos dicionários alemães analisados, e cujo significado agrega os valores reforçativo (além disso) e digressivo (diga-se de passagem; a propósito; por falar nisso), deixando de lado o retificativo.

Ora, tendo em conta que o contexto mais frequente para a ocorrência de 'aliás' é o contexto $\mathrm{C}$ (reforçativo), poderíamos pensar que as traduções preferenciais seriam außerdem e zudem, os MD alemães mais vocacionados para marcar o aditamento de informação; por outro lado, consideremos que, de acordo com o projeto Wortschatz Uni Leipzig8 ${ }^{8}$ de todas as opções possíveis, a expressão im Übrigen é uma das menos frequentes em alemão, dado que podemos comprovar no quadro seguinte.

Quadro 4

\begin{tabular}{|l|l|l|l|}
\hline auch & 2169078 & ferner & 4450 \\
\hline bereits & 338708 & überdies & 3466 \\
\hline zudem & 74576 & im Übrigen & $\mathbf{2 8 2 3}$ \\
\hline außerdem & 67726 & abgesehen davon & 901 \\
\hline übrigens & 29390 & nebenbei bemerkt & 133 \\
\hline darüber hinaus & 18771 & & \\
\hline
\end{tabular}

Então por que razão é a preferida dos tradutores? Consta apenas de um dos dicionários bilingues, mas o seu uso sugere que é a solução padrão, sobretudo se tivermos em conta que é a preferencial para traduzir todos os valores de 'aliás'. Estas observações sugerem que o trabalho dos tradutores/intérpretes procura a relevância ótima (Gutt, 1991: 199), isto é, procura o melhor efeito contextual com o menor custo de processamento para o ouvinte/leitor.

Dadas as constrições do processo tradutivo em que se vê envolvido (a atenção ao discurso do falante original, o processamento dessa informação em tempo real, a urgência em codificá-la numa

${ }^{8}$ Wortschatz (2016): Deutscher Wortschatz - Portal, http://wortschatz.uni-leipzig.de 
língua diferente, a busca de soluções para problemas iminentes e a pressão do tempo), o tradutor/intérprete tende a optar por um MD cujo valor procedimental é mais lato, não limitando assim, em demasia, o leque de potenciais sentidos e permitindo ao ouvinte/ leitor maior latitude interpretativa.

Em segundo lugar, verifica-se que, dos 184 casos de 'aliás', 38 não são sequer traduzidos, (cerca de $21 \%$ ), ou seja, mais de um quinto das ocorrências. A omissão do marcador verifica-se sobretudo nos contextos em que ele assume um valor claramente digressivo, como é visível no exemplo seguinte, acompanhado da respetiva tradução:

A proposta do Parlamento Europeu contempla aspectos que melhoram o projecto apresentado pelo Conselho, como por exemplo, o reforço das verbas para a política de coesão, como aliás também propusemos, embora devendo sublinhar-se que a sua aplicação efectiva é em grande medida posteriormente desvirtuada para a concretização dos objectivos da agenda neoliberal que é a Estratégia de Lisboa, o que firmemente rejeitamos.

Der Vorschlag des Parlaments beinhaltet Aspekte, die den vom Rat vorgelegten Entwurf verbessern, wie die Erhöhung der Mittelzuweisungen für die Kohäsionspolitik, die $\varnothing$ auch wir vorgeschlagen haben. Gleichwohl sollten wir betonen, dass deren wirksame Umsetzung später größtenteils unterlaufen wird, um die Ziele der neoliberalen Agenda der von uns abgelehnten Lissabon-Strategie zu erreichen. (07-10-23 <SPEAKER ID="228" NAME="Pedro Guerreiro" AFFILIATION="GUE/NGL">)

No entanto, esse apagamento ocorre também em alguns contextos em que é permitida uma interpretação digressivo-reforçativa e até claramente reforçativa, como se atesta, respetivamente, através dos exemplos seguintes e das subsequentes traduções: 
Somos testemunhas, neste Parlamento, da excelente colaboração que o Presidente da Comissão Europeia e esta Comissão Europeia têm assumido com o Parlamento Europeu, como funcionou bem a cooperação com todos os deputados, os deputados portugueses são disso testemunha, os deputados do PSD orgulham-se de terem contribuído para o bom sucesso desta Presidência.

Portugal deu, aliás, sempre o seu melhor quando exerceu a Presidência do Conselho. Foi assim em 92 com Cavaco Silva e o então Ministro dos Negócios Estrangeiros João de Deus Pinheiro, foi assim em 2000, com o Primeiro-Ministro António Guterres, foi assim em 2007, na terceira Presidência do Conselho da União, com José Sócrates e o Ministro Luis [sic] Amado.

Wir konnten uns in diesem Parlament selbst von der hervorragenden Zusammenarbeit des Präsidenten der Europäischen Kommission und der Kommission selbst mit dem Parlament überzeugen; alle Europaabgeordneten haben gut zusammengearbeitet - das können die portugiesischen Abgeordneten bezeugen -, und die PSD-Mitglieder sind stolz darauf, dass sie zum Erfolg dieser Präsidentschaft beitragen konnten.

Portugal hat $\varnothing$ stets sein Bestes gegeben, wenn es den Ratsvorsitz geführt hat. Das war 1992 der Fall unter Herrn Cavaco Silva und dem damaligen Außenminister João de Deus Pinheiro, das war im Jahr 2000 der Fall unter Ministerpräsident António Guterres und das war 2007 der Fall, als wir das dritte Mal den Ratsvorsitz unter Leitung von José Sócrates und Minister Luis Amado innehatten. (07-12-18 <SPEAKER ID="031" NAME="Carlos Coelho" AFFILIATION="PPE-DE">)

Apesar do [sic] acordo introduzir prazos processuais estritos, estabelecer taxas de visto preferenciais, incluindo uma isenção total da taxa de visto para certas "categorias de pessoas" (?) e 
prever um procedimento simplificado para diferentes situações, fica aquém do que se exigiria e do que necessitam milhares e milhares de cidadãos ucranianos.

Aliás, como os relatores deixam a entender, a necessidade que se coloca é a da efectiva implementação de medidas com vista à facilitação de vistos para grupos mais vastos da sociedade ucraniana, até a um regime de isenção da obrigação de visto, sem discriminações, como a Ucrânia fez relativamente a cidadãos dos diferentes países da UE.

Auch wenn das Abkommen strenge Verfahrensfristen einführt, ermäßigte Visagebühren einschließlich einer vollständigen Befreiung von der Visagebühr für bestimmte Personengruppen (?) festsetzt und in einigen Fällen ein vereinfachtes Verfahren vorsieht, ist es weit entfernt von dem, was erforderlich ist und was Tausende von Bürgern der Ukraine bräuchten.

Die Berichterstatter haben ø nicht erkannt, wie notwendig es ist, dass Maßnahmen zur Visaerleichterung für breitere Gruppen der ukrainischen Gesellschaft bzw. eine nicht diskriminierende Visabefreiung erforderlich sind, wie sie von der Ukraine bei Bürgern einzelner EU-Länder praktiziert wird. (07-11-13 <SPEAKER ID="123" NAME="Pedro Guerreiro " AFFILIATION="GUE/NGL">)

O desaparecimento do MD suscita algumas reflexões. Em primeiro lugar, este dado vem corroborar os estudos já efetuados e que afirmam que a omissão constitui uma estratégia tradutiva bastante frequente (Bazzanella et al., 2007: 11; Aijmer, 2008: 95; Furkò, 2014: 182).

Em segundo lugar, apesar de a sua omissão ocorrer tendencialmente em contextos de natureza digressiva, não deixa de causar alguma perplexidade o facto de ocorrer também em contextos de cariz reforçativo, o que vem a ter, obviamente, implicações no domínio da própria argumentação. Como explicar a ausência de um 
marcador que introduz o argumento decisivo? Se essa instrução não é dada ao ouvinte/leitor, que tipo de interpretação fará ele relativamente à sequência de argumentos que se lhe apresenta?

De acordo com Hellberg (2013: 9), "[e]ven if pragmatic markers are usually grammatically optional and their lexical meaning may have been reduced, they still serve important pragmatic functions." De facto, ao funcionarem como pista interpretativa, os MD desempenham um papel fundamental no processo interpretativo, na construção das inferências, e a sua ausência resultará seguramente numa interpretação diferente.

É ainda pertinente assinalar que a omissão do MD é anómala, tendo em conta as diretivas que regulamentam a interpretação simultânea e que preveem uma reprodução correta, completa e precisa do dito (Setton \& Dawrant, 2016a; 2016b). Se o MD é necessário para uma avaliação mais fina do sentido do enunciado, então como se justifica o seu apagamento?9 Será, como afirma Gile (1999), um sinal de que o intérprete está a trabalhar perto do ponto de saturação?

A ocorrência de 'aliás' em início absoluto de frase poderia constituir uma explicação para esta estratégia de omissão, pois o tradutor-intérprete não sabe ainda, no momento em que ouve o marcador, qual dos sentidos vai ser ativado naquele contexto e, mais tarde, quando compreende qual dos valores foi atualizado já é demasiado tarde para o traduzir. Tal constrição não é, contudo, preponderante nos exemplos em causa, pois apenas em oito das ocorrências (que correspondem a omissão) 'aliás' ocupa tal posição sintática. Paralelamente, verificou-se que, em outros exemplos nos quais 'aliás' ocupa a posição de início absoluto, ele é traduzido por um leque bastante variado de outras soluções - embora a

9 Serão as nuances prosódicas suficientes para transmitir, de outra forma, o valor do marcador? Sem acesso a dados orais, não é possível responder a esta pergunta. 
mais frequente seja im Übrigen - o que impede a construção de um padrão de tradução e impossibilita o desenho de conclusões consistentes.

Observemos agora o conjunto das quatro expressões que, em número já bastante inferior, são usadas para traduzir 'aliás': auch; übrigens; außerdem e zudem. Impõe-se desde já avançar a tradução (conquanto descontextualizada) que estas expressões têm em português, a saber:

Quadro 5

\begin{tabular}{|l|l|}
\hline auch & também \\
\hline übrigens & a propósito / diga-se de passagem \\
\hline außerdem & além disso \\
\hline zudem & além disso \\
\hline
\end{tabular}

Compreende-se facilmente que enquanto auch, außerdem e $z u$ dem abrangem melhor os sentidos de adição e reforço, übrigens traduz melhor o sentido digressivo, distanciando-se claramente dos outros três. Refira-se ainda que nenhum deles é tão polifuncional como 'aliás'.

Ao cotejarmos todas estas informações, sobressai a maior amplitude semântica do marcador im Übrigen, que recobre um maior leque de valores, e a maior especificidade semântica dos quatro últimos (auch; übrigens; außerdem e zudem). E embora exista, como vimos pela análise lexicográfica, pelo menos uma expressão capaz de dar conta do cluster de sentidos reforço-retificação (beziehungsweise) destaca-se ainda a ausência de uma tradução alemã que dê conta deste valor (contexto D), uma vez que nenhuma das opções dos tradutores tem valor retificativo. 
O Quadro 6 dá conta desta distribuição:

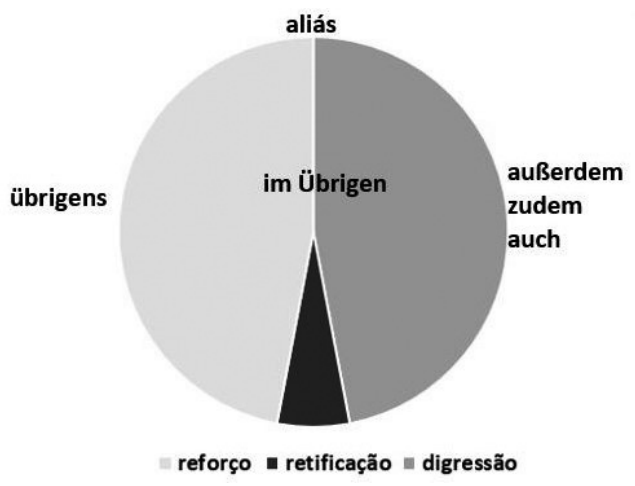

É notório que 'aliás' pode veicular três sentidos distintos, se bem que frequentemente sobrepostos - embora aqui compartimentados para efeitos de clareza expositiva - enquanto im Übrigen abarca apenas dois desses sentidos; übrigens, por sua vez, apenas um deles, e außerdem, zudem e auch, o outro.

O grupo de expressões designado por 'outros', no Quadro 3, abrange 18 itens diferentes. Embora tratando-se de itens diversificados, podemos ensaiar a tentativa de os agregar tendo em conta os seus valores semânticos. Assim, conseguimos identificar um grupo de expressões cujo denominador comum é a possibilidade de serem parafraseados por außerdem, e que têm, grosso modo, valor de adição: darüber, darüber hinaus, ebenfalls, ferner, überdies.

Um segundo grupo aproxima-se mais facilmente de im Übrigen, tendo, como traço partilhado, o valor digressivo: ja, ja auch, nebenbei bemerkt, übrigens.

Sob esta ótica, poderemos então reformular as informações previamente avançadas relativamente às soluções procuradas pelos tradutores. De acordo com este rearranjo, os equivalentes preferenciais são os que integram o grupo im Übrigen e übrigens (86 opções) e, em segundo lugar, os que integram o grupo de außerdem (com 50 opções), surgindo então, em terceiro lugar, a omissão do MD. 
Gostaríamos ainda de realçar algumas traduções que se desviam, claramente, do sentido original, comprometendo, portanto, a exigência de uma tradução fidedigna. Nestes casos, 'aliás' é traduzido através de diferentes expressões que, como veremos, impõem uma leitura muito específica e que se encontra já muito distante dos valores do marcador na LP. Atentemos em dois exemplos:

Aliás, fica mais caro remediar do que prevenir.

Heilen ist eindeutig kostspieliger als Vorbeugen.

(A cura é claramente/sem dúvida mais cara do que a prevenção) (07-09-03 <SPEAKER ID="069" NAME="Edite Estrela" AFFILIATION="PSE">)

Neste exemplo, a expressão eindeutig possui um valor modal, de natureza epistémica, que está ausente de 'aliás‘.

Esta situação é ainda agravada pela reserva de verbas que a Comissão faz para si, o que, aliás, aliado às acções pontuais, apenas deixa para as organizações três milhões de euros, verba manifestamente diminuta.

Erschwerend kommt hinzu, daß die Kommission eine Mittelreserve für sich einführt. Zusammen mit den punktuellen Maßnahmen bleiben dann für die Organisationen nur noch drei Millionen Euro, eine offenkundig unzureichende Finanzausstattung.

(...Juntamente com as medidas pontuais ficariam, então / assim / nestas circunstâncias, para as organizações apenas 3 milhões...) (00-03-17 <SPEAKER ID=21 NAME="Figueiredo">)

A expressão dann pode ser traduzida por qualquer uma das expressões propostas, sendo verdade que a última já não é conside- 
rada $\mathrm{MD}$, embora, em qualquer dos casos, o sentido veiculado seja o consequencial-conclusivo que 'aliás' não possui.

\section{Conclusões}

A análise das ocorrências de 'aliás' nos textos originais permitiu-nos confirmar a existência de todos os sentidos do MD em uso na atual sincronia do português e constatar que ele opera em diferentes planos do significado, nomeadamente no plano do dizer, da enunciação, através da operação de reformulação-retificação, no que se consuma uma dimensão meta; e no plano do dito, do enunciado, através da operação de adição de informação (valores digressivo e reforçativo). Analisados esses dados, pudemos ainda concluir que esses sentidos surgem, na sua esmagadora maioria, agregados em clusters, e que nem sempre é fácil apreender qual o sentido mais saliente.

Por seu turno, a análise das traduções permitiu também delinear algumas conclusões interessantes. Em primeiro lugar, evidenciou que as escolhas dos tradutores se encontram muito distantes das sugestões propostas pelos dicionários. Tal distância é reveladora das lacunas e das omissões presentes nos dicionários, sempre aquém das necessidades tradutivas dos profissionais, e comprova que, para traduzir um MD, os tradutores-intérpretes se apoiam mais na função, contextualizada, da partícula.

Em segundo lugar, pudemos verificar que, em alemão, é possível encontrar expressões capazes de traduzir cada um dos valores de 'aliás', per se, e que até se encontra um equivalente capaz de conjugar dois desses sentidos (im Übrigen); todavia, comprovou-se não existir, na LC, nenhum equivalente que combine os três valores do MD português. Esta inexistência, a polifuncionalidade do MD e a sua extrema sensibilidade aos contextos dificultam o trabalho do 
tradutor-intérprete que, em tempo real e sob pressão, tem problemas em identificar o sentido e/ou cluster de sentidos ativado e em escolher o correspondente mais adequado. Nestas circunstâncias, a opção tradutiva recai sobre o MD im Übrigen, ou seja, sobre aquele que apresenta uma correspondência 'quase' perfeita com o português 'aliás'.

Se pensarmos, no entanto, que o contexto D (reforçativo-retificativo) é o terceiro mais frequente no corpus e considerando, por um lado, que im Übrigen não tem esse valor retificativo e, por outro lado, que nenhum dos marcadores de natureza reformulativa/retificativa propostos pelos dicionários foi utilizado pelos tradutores, podemos também concluir que o valor reformulativo-retificativo se perde completamente nas traduções, restando apenas a leitura de reforço, o que, não desvirtuando a intenção do falante original, ainda assim empobrece claramente o leque de possibilidades interpretativas. Este mesmo comentário é também extensivo às muitas omissões encontradas na tradução, pois o apagamento do MD na LC resultará certamente num discurso menos rico e mais neutro, isto é, destituído de alguma informação de natureza pragmática que auxilia o processo interpretativo.

Os resultados aqui apresentados devem, naturalmente, ser confirmados através da análise de outros géneros textuais, de modo a obtermos um conhecimento mais amplo e rigoroso acerca do MD e dos seus valores.

\section{Referências}

Aijmer, Karin (2008). Translating discourse particles: a case of complex translation. In Gunilla Anderman e Margaret Rogers (Eds.), Incorporating corpora: The Linguist and the Translator. Clevedon/Tonawanda/Ontario: Multilingual Matters

Aijmer, Karin, Foolen, Ad e Simon-Vandenbergen, Anne-Marie (2006). Pragmatic markers in translation - a methodological proposal. In Kerstin Fischer (Ed.), Approaches to Discourse Particles. Oxford: Elsevier, 101-114. 
Almeida, Daniel M. (2013). O marcador do discurso aliás e suas possibilidades para a língua espanhola. Entretextos, vol. 13, n. ${ }^{\circ}$ 2, 344-362.

Andersen, Gisle (2001). Pragmatic Markers and Sociolinguistic Variation: A Relevancetheoretic approach of the language of adolescents. Amsterdam: John Benjamins.

Bazzanella, Carla et alii (2007). Italian "allora», French "alors»: functions, convergences, and divergences. Catalan Journal of Linguistics, 6, 9-30.

Bechara, Evanildo (2005). Moderna Gramática Portuguesa. Rio de Janeiro: Lucerna.

Chaume, Frédéric (2004). Discourse Markers in Audiovisual Translating. Meta : journal des traducteurs / Meta: Translators' Journal, vol. 49, $\mathrm{n}^{\circ} 4,843-855$.

Cunha, Celso e Cintra, Lindley (1984/1991). Nova Gramática do Português Contemporâneo. Lisboa: Sá da Costa (8. $\left.{ }^{\mathrm{a}} \mathrm{ed}.\right)$.

Degand, Liesbeth. (2009). On describing polysemous discourse markers. What does translation add to the picture? In Stef Slembrouck, Miriam Taverniers, Mieke Van Herreweghe (Eds.), From will to well. Studies in Linguistics offered to Anne-Marie Simon-Vandenbergen. Gent: Academia Press, 173-183.

Fernandes, Ivani C. S. (2005). Estudio comparativo de los marcadores del discurso en el español y en el portugués: el caso de los reformuladores en la prensa escrita. In: Interlingüística, n. 16, (2), 1019-1028.

Fraser, Bruce. (1999). What are discourse markers? Journal of Pragmatics, 31: 931-952.

Furkò, Bálint Péter (2014). Perspectives on the Translation of Discourse Markers. A case study of the translation of reformulation markers from English into Hungarian. Acta Universitatis Sapientiae, Philologica, 6, 2, 181-196.

Gile, Daniel (1999). Testing the Effort Models' tightrope hypothesis in simultaneous interpreting - a contribution. Hermes, 23, 153-172.

Gutt, Ernst-August. (1991). Translation and Relevance: Cognition and Context. Oxford: Basil Blackwell.

Hansen, Maj-Britt Mosegaard (1998). The Function of Discourse Particles. Amsterdam: John Benjamins.

Hellberg, Sanna Estling (2013). Translating Pragmatic Markers - or whatever you want to call them. Texto disponível online em <http://www.sannahellberg.com/ wp-content/uploads/2014/12/Pragmaticmarkers.pdf $>$

Hölker, Klaus. (1991). Französisch: Partikelforschung [Research on French particles]. Lexikon der Romanistischen Linguistik [Lexicon of Romance Linguistics], 5 (1) Tübingen: Niemeyer, 77-88.

Koch, Ingedore G. (1984). Argumentação e linguagem. São Paulo: Cortez Editora.

Koehn, Phillipp (2005). Europarl: A parallel corpus for statistical machine translation. Proceedings of the Tenth Machine Translation Summit, September 13-15. Phuket, Thailand, 79-85.

Lopes, Ana Cristina Macário (2010). Aliás: évolution d'un marqueur de discours en portugais. Comunicação apresentada no Coloquio Internacional Marcadores del Discurso en las Lenguas Románicas (Madrid, Univ. Complutense, 5-7 de mayo de 2010). 
Lopes, Ana Cristina Macário (2015). Aliás: contribution à l'étude diachronique d'un marqueur du discours du Portugais. In Margarita Borreguero-Zuloaga e Sonia Gómez-Jordana Ferary (Eds.), Marqueurs du discours dans les langues romanes: une approche contrastive. Limoges: Lambert-Lucas, 2014.

Ponce de León, Rogelio \& Duarte, Isabel Margarida (2013). Aliás / alias: diferencias de empleo en portugués y en español. In Nicole Delbecque, Marie-France Delport e Daniel Michaud Maturana (Eds.). Du signifiant minimal aux textes. Etudes de linguistique ibero-romane. Leuven: Lambert-Lucas, 137-152.

Schiffrin, Deborah (1987). Discourse Markers. Cambridge: Cambridge University Press.

Schoroup, Lawrence (1999). Discourse Markers. Lingua 107 (3-4), 227-265.

Setton, Robin \& Dawrant, Andrew (2016a). Conference Interpreting - A Complete Course. Amsterdam: John Benjamins.

Setton, Robin \& Dawrant, Andrew (2016b). Conference Interpreting: A Trainer's Guide. Amsterdam:John Benjamins.

Simon-Vandenbergen, Anne-Marie e Aijmer, Karin (2004). A model and a methodology for the study of pragmatic markers: the semantic field of expectation. Journal of Pragmatics, 36, 1781-1805.

Snell-Hornby, Mary (1988/1995). Translation Studies: An Integrated Approach. Amsterdam: John Benjamins.

Steele, David (2015). Improving the Translation of Discourse Markers for Chinese into English. Proceedings of NAACL-HLT 2015 Student Research Workshop (SRW). Denver, Colorado. Association for Computational Linguistics, 110-117.

\section{Dicionários}

Dicionário bab.la (http://pt.bab.la/dicionario/portugues-alemao/)

Dicionário da Língua Portuguesa Contemporânea. Academia das Ciências de Lisboa (2001).

Dicionário Houaiss da Língua Portuguesa. Lisboa: Círculo de Leitores (2002).

Infopédia. Grupo Porto Editora. (https://www.infopedia.pt/).

Langenscheidt-Redaktion (Berlin/München), Hoepner, L., Kollert, A. M. C., \& Weber, A. (1999). Langenscheidt Taschenwörterbuch Portugiesisch: portugiesisch-deutsch, deutsch-portugiesisch. Langenscheidt.

LEO Wörterbuch Portugiesisch-Deutsch. LEO GmbH. (https://dict.leo.org/portugiesischdeutsch).

PONS Online-Wörtebuch. PONS GmbH. (http://de.pons.com/). 